\title{
The annual cycle in lower stratospheric temperatures revisited
}

\author{
S. Fueglistaler ${ }^{1,}{ }^{*}$, P. H. Haynes ${ }^{1}$, and P. M. Forster ${ }^{2}$ \\ ${ }^{1}$ Applied Mathematics and Theoretical Physics, University of Cambridge, Cambridge CB3 OWA, UK \\ ${ }^{2}$ School of Earth and Environment, University of Leeds, LS2 9JT, UK \\ *now at: Department of Geosciences, Princeton University, USA
}

Received: 14 September 2010 - Published in Atmos. Chem. Phys. Discuss.: 9 November 2010

Revised: 5 April 2011 - Accepted: 9 April 2011 - Published: 21 April 2011

\begin{abstract}
Observed lower stratospheric temperatures show a prominent annual cycle. The cycles in the tropics and Northern Hemisphere are in phase and the cycle in the Southern Hemisphere has the opposite phase. In an elegant and influential paper, Yulaeva, Holton and Wallace (1994) explained the observed pattern as a direct consequence of hemispheric asymmetries in the dynamical forcing of the stratospheric circulation. They showed that in Microwave Sounding Unit channel 4 (weighting centered in the lower stratosphere) data the combined extratropical and the tropical temperature cycle nearly compensate and interpreted the out-of-phase temperature variations between tropics and extratropics as the temperature response to an annual cycle in the wave driven residual circulation. We show that the near-compensation of temperature variations observed by Yulaeva et al. (1994) is artefact of the weighting function of the MSU-4 channel and does not hold on individual pressure levels. We discuss in detail the conditions required that temperature variations compensate, and what insights can be obtained from analysis of tropical, extratropical and global mean temperature variations. Dynamically induced seasonal variations of lower stratospheric ozone lead to an amplification of the seasonal temperature cycle particularly in the tropics. The latitudinal structure of static stability also induces a significant deviation from compensation of tropical and combined extratropical temperature variations. In line with Yulaeva et al. (1994) we affirm that the see-saw pattern in the annual cycles of tropical and combined extratropical temperatures provides an important pointer to mechanistic models for interannual variability and trends, but additionally conclude that the feedback of dynamically induced ozone variations on temperatures and the latitudinal structure of static stability should be included as leading order processes in such models.
\end{abstract}

Correspondence to: S. Fueglistaler (stf@princeton.edu)

\section{Introduction}

Observed tropical lower stratospheric temperatures show a prominent annual cycle (Reed and Vlcek, 1969), rather than a semiannual cycle as might have been expected from the annual progression of the latitude of maximum solar zenith angle or indeed of the latitude of the Intertropical Convergence Zone. Furthermore the annual cycle is out of phase with the annual variation in sun-earth distance. (Temperatures maximise during boreal summer, whereas distance minimizes in boreal winter). A number of hypotheses have been proposed to explain this surprising observation (for a summary see e.g. Yulaeva et al., 1994 and Fueglistaler et al., 2009b).

In an elegant and influential paper Yulaeva et al. (1994) (henceforth YHW94) analysed temperatures from the MSU4 channel, which is sensitive to lower stratospheric temperatures. They observed that the tropics, and the combined extratropics, each have an annual cycle with amplitude $\sim 2 \mathrm{~K}$. These two cycles are almost perfectly out of phase and there is almost perfect compensation between them, so that the global mean annual cycle has an amplitude only of $\sim 0.2 \mathrm{~K}$, i.e. one order of magnitude smaller. YHW94 noted that, at least under the simplest possible approximation (discussed in detail below) the dynamical heating term in the zonal mean thermodynamic equation must vanish in the (area-weighted) global mean. They went on to suggest that the "compensated" part of the annual temperature variations, which in the MSU-4 data appeared as the dominant part, was driven by the annual cycle in dynamical heating, or more specifically by the annual cycle in the lower stratospheric BrewerDobson circulation. YHW94 suggested that the latter variation was driven by seasonal differences in extratropical planetary wave driving, which tends to be largest in the winter and spring seasons in each hemisphere, but relatively larger in Northern Hemisphere than in the Southern Hemisphere, implying an annual cycle in the total wave driving. There remains an ongoing debate on which waves are most important

Published by Copernicus Publications on behalf of the European Geosciences Union. 
for the annual cycle in wave driving (e.g. Norton, 2006; Randel et al., 2008) but the annual cycle in the Brewer-Dobson circulation is well-established.

Further, YHW94 deduced that any annual cycle in the global average temperature on a given horizontal surface must be due to changes in radiative equilbrium temperature or radiative relaxation rate. They suggested that the (small) annual cycle in global average MSU-4 temperatures might be caused by the radiative effect of the seasonal cycle of ozone in the tropical lower stratosphere. To support this argument they showed the observations of seasonal variations in total ozone that were available at the time (implicitly assuming that these were a useful indication of seasonal variations of ozone in the lower stratosphere).

Here, we revisit the analysis of YHW94, and show that the high degree of compensation between tropical and extratropical temperature variations in MSU-4 temperatures is fortuitous. We discuss in detail how the latitudinal structure of the thermal stratification, dynamical variability and variability in the radiative budget affects the relation between tropical and combined extratropical temperatures. Implications for the interpretation of trends in stratospheric temperatures and dynamics are discussed.

\section{Data and method}

We use temperature data from the new interim reanalysis (ERA-Interim, see Simmons et al., 2006; Fueglistaler et al., 2009a) of the European Centre for Medium-range Weather Forecasts (ECMWF). The data are interpolated from the original model resolution (T256, 60 levels) to a regular $1^{\circ} / 1^{\circ}$ (longitude/latitude) grid on pressure levels. All data are averaged to zonal average, monthly mean fields. Results shown here based on ERA-Interim are nearly identical to those obtained when using the widely known ERA-40 reanalysis (not shown).

The climatological mean annual cycle is determined from data over the period 1994-2006. Over this period ERAInterim lower stratospheric temperatures are stable (see Liu et al., 2010; the introduction of Constellation Observing System for Meteorology, Ionosphere and Climate (COSMIC) temperature data at the end of 2006 led to a drift particularly around $100 \mathrm{hPa}$ ), and are not affected by the enhanced stratospheric aerosol loading following the eruption of Pinatubo in 1991. Interannual variability (i.e. time variation after subtraction of the climatological mean annual cycle) are shown for the full period of currently available data from ERAInterim (1989-2009).

In order to compare results with those of YHW94, we use the MSU-4 weighting function provided by Remote Sensing Systems (RSS, http://www.remss.com/) to produce simulated MSU-4 data from ERA-Interim, following the procedure described by Fu and Johanson (2005).
Following YHW94, we discuss the temperature variability in terms of global mean, tropical mean, and combined extratropical mean. These averages are calculated from the area weighted temperatures. For the combined extratropics

$$
\langle T(\phi)\rangle_{\mathrm{ext}} \equiv \frac{1}{2}\left(\int_{-90}^{-30} \cos (\phi) T(\phi) d \phi / \int_{-90}^{-30} \cos (\phi) d \phi+\int_{30}^{90} \ldots\right)
$$

where $\phi$ is latitude, $T$ is temperature, and the operator $\left\langle\right.$. $>_{\mathrm{x}}$ denotes the area-weighted average over area " $\mathrm{x}$ ". Global $\langle T(\phi)\rangle_{\text {glo }}$ and tropical $\langle T(\phi)\rangle_{\text {tro }}$ means are calculated accordingly. Note that the separation at $30^{\circ}$ latitude is partly motivated by the meridional structures of temperature and tracer fields, but is also simply a convenient separation as it halves the globe, such that:

$\langle T(\phi)\rangle_{\mathrm{glo}}=\frac{1}{2}\left(\langle T(\phi)\rangle_{\text {tro }}+\langle T(\phi)\rangle_{\mathrm{ext}}\right)$

In particular, note that the "turnaround" latitude of the circulation (i.e. where diabatic ascent turns to diabatic descent) is not exactly at $30^{\circ}$ latitude. Rather, its position varies with season and is generally slightly further polewards (see e.g. Rosenlof et al., 1995; Fueglistaler et al., 2009a).

Throughout this paper we work with zonal mean quantities, and for simplicity we omit the frequently used overbar to denote zonal means. Similarly, we do not use a specific symbol (e.g. asterisk) for deviations from time-means. In cases where this may lead to confusion we explicitly explain the meaning of symbols.

The impact of ozone variations on the radiative equilibrium temperature is calculated with two 2-broadband radiative transfer codes, namely the Edwards-Slingo scheme as used in the UK Met Office Unified Model (Edwards and Slingo, 1996) and an updated version of the Fu-Liou code (Fu and Liou, 1992). Results using the two codes are very similar, and we show here only those using the EdwardsSlingo code. We estimate the change in radiative equilibrium temperature from the temperature change in the so-called "Seasonally Evolving Fixed Dynamical Heating" (SEFDH) approximation (Forster et al., 1997). The SEFDH approximation assumes that any dynamical heating present does not change when tracer concentrations are changed. At each level above $200 \mathrm{hPa}$ a climatological dynamical heating term is calculated for each day of the year as equal and opposite to the radiative heating on that day plus any temperature tendency from the annual cycle. This is then "fixed" when trace gases are perturbed, and the combination of this fixed dynamical heating and the new radiative heating rates gives an altered annual cycle. The trace gas perturbation here is the annual cycle in stratospheric ozone concentrations, which we have calculated from the climatological mean (period years 1994-2000) annual cycle of zonal mean stratospheric ozone measured by Halogen Occultation Experiment (HALOE, Russell et al., 1993). 


\section{The seasonality of temperatures and the role of the MSU-4 weighting function}

Figure 1 shows the mean and annual cycle (anomaly) of the simulated MSU-4 temperature. The area-weighted anomalies shown in Fig. 1b recover the pattern observed by YHW94 almost perfectly (compare with Fig. 4 of YHW94). Fig. 1c shows the annual cycle of global mean, tropical and extratropical mean simulated MSU-4 temperatures. Again, the results are similar to those presented by YHW94: tropical and extratropical temperature variations have an amplitude of about $2 \mathrm{~K}$, whereas the global mean has an amplitude of about $0.2 \mathrm{~K}$ only. The exact timing of the peaks in particular of the global mean temperature anomaly is slightly different than in the data shown by YHW94, but this small difference in phase may not be surprising given that the global mean is the difference of two large terms. Overall, the simulated MSU-4 temperature reconstructs faithfully the MSU-4 observations presented by YHW94, which allows us to study the problem with ERA-Interim temperature data and thereby take advantage of the much higher vertical resolution than MSU-4 measurements.

Figure 2 shows the same information as Fig. 1, except that it is for one pressure level at $67 \mathrm{hPa}$ in the lower stratosphere. Comparison between the two figures shows that the annual mean, and the pattern of the annual cycle are similar. Also, the annual cycle of the combined extratropics (Figs. 1c, 2c, blue) is quite similar, whereas that of the tropics is about a factor 2 larger at $67 \mathrm{hPa}$. Consequently, the global mean temperature shows an annual cycle of amplitude $1 \mathrm{~K}$. In contrast to the situation with MSU-4 temperatures, the amplitude of global mean temperature variation is of the same order of magnitude as that in the tropics, or combined extratropics.

Figure 3 shows the vertical structure of the seasonality of area-averaged temperatures, which reveals why the MSU-4 temperature data show a very high degree of compensation between tropics and extratropics, whereas individual pressure levels do not show the same behaviour. In the extratropics, the annual cycle of temperatures is roughly in-phase throughout the depth of the MSU-4 weighting function. In contrast, the tropical temperatures show very little seasonality below about $100 \mathrm{hPa}$. Moreover, above $20 \mathrm{hPa}$ a semiannual pattern prevails. Hence, the MSU-4 instrument integrates over layers with coherent phase in the extratropics, while the integration in the tropics gives a strong attenuation of the annual cycle signal that dominates the layer $100-50 \mathrm{hPa}$. By coincidence, the MSU-4 weighting yields a near perfect compensation between tropics and combined extratropics.

\section{Implications}

In the following we discuss the governing equations in more detail than YHW94. We show under what conditions compensation between tropical and extratropical tempera-
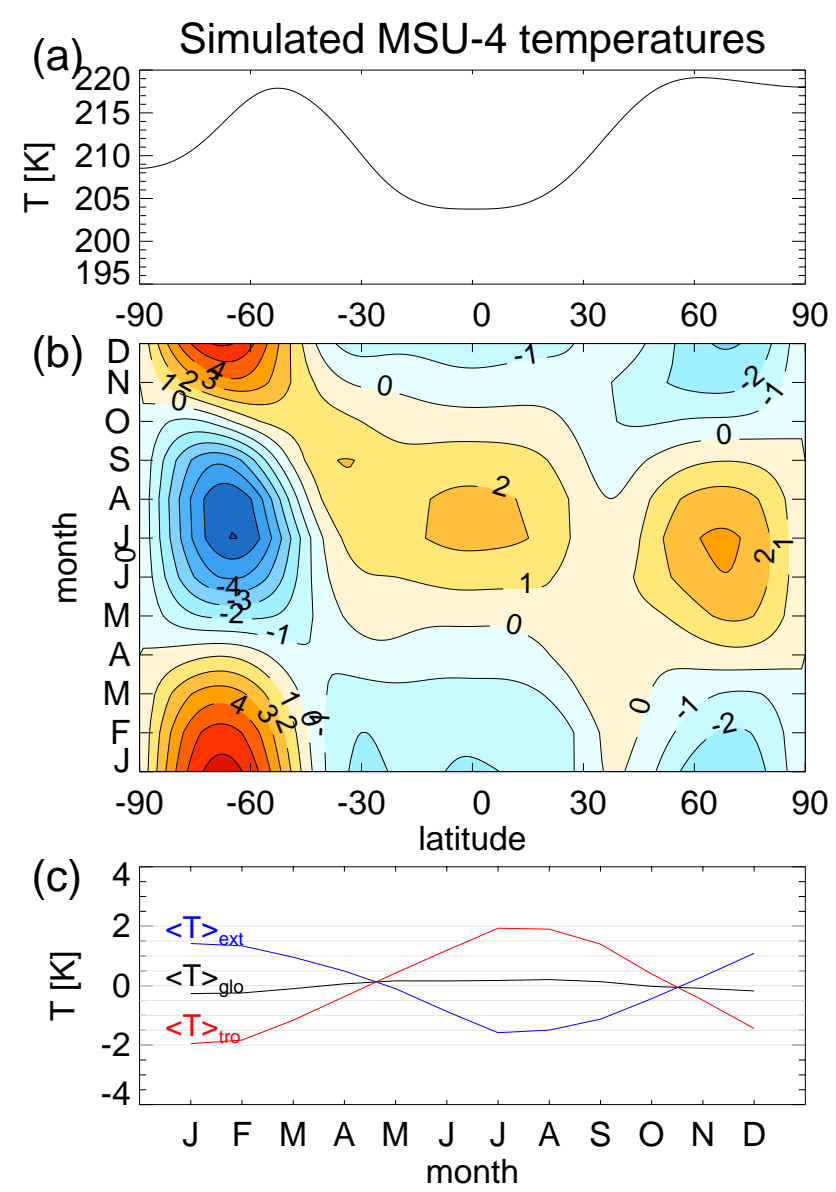

Fig. 1. Climatological mean annual cycle of simulated MSU-4 temperatures. (a) Latitudinal structure of annual mean temperature. (b) Latitudinal structure of cosine(latitude)-weighted temperature anomalies (contour increments $1 \mathrm{~K}$, color coding increments $0.5 \mathrm{~K}$ ). (c) Area weighted anomalies for combined extratropics $<T>$ ext $\left(90^{\circ} \mathrm{S}-30^{\circ} \mathrm{S}, 30^{\circ} \mathrm{N}-90^{\circ} \mathrm{N}\right.$, blue), tropics $<T>_{\text {tro }}\left(30^{\circ} \mathrm{S}-30^{\circ} \mathrm{N}\right.$, red), and global $<T>_{\text {glo }}\left(90^{\circ} \mathrm{S}-90^{\circ} \mathrm{N}\right.$, black).

tures occurs and clarify which terms can induce departures from compensation. We arrive at different conclusions to YHW94 concerning the importance of terms affecting temperature variations, but we concur with YHW94 on an important role of the residual circulation in inducing temperature contrasts, and in annual variations of those contrasts, between tropics and extratropics.

\subsection{The relation between diabatic mass flux and temperature}

In the quasi-geostrophic, transformed Eulerian mean set of equations, the thermodynamic energy equation may be written as (see Andrews et al. (1987), Eq. 7.2.1b):

$Q=\left(N^{2} H / R\right) \cdot w^{*}+\frac{\partial T}{\partial t}$ 

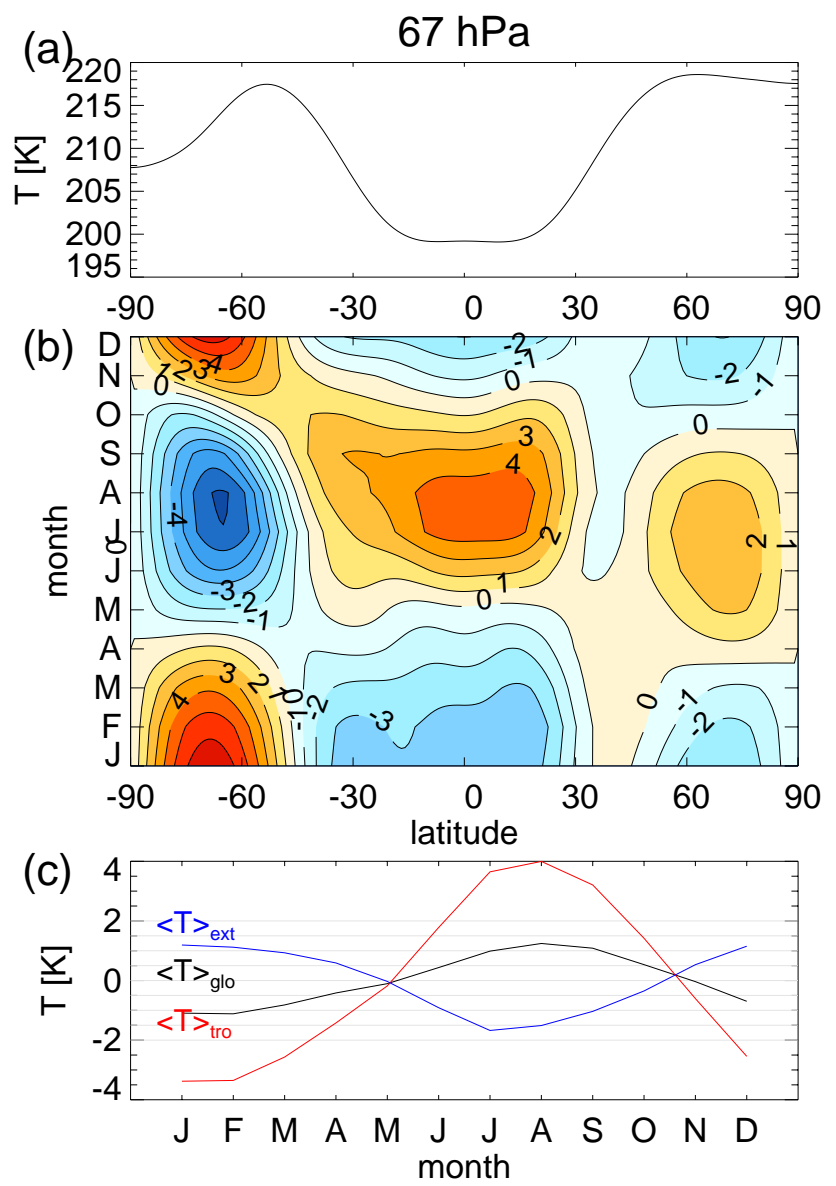

Fig. 2. Climatological mean annual cycle of ERA-Interim temperatures at $67 \mathrm{hPa}$. (a) Latitudinal structure of annual mean temperature. (b) Latitudinal structure of cosine(latitude)-weighted temperature anomalies (contour increments $1 \mathrm{~K}$, color coding increments $0.5 \mathrm{~K})$. (c) Area weighted anomalies for combined extratropics $<T>$ ext $\left(90^{\circ} \mathrm{S}-30^{\circ} \mathrm{S}, 30^{\circ} \mathrm{N}-90^{\circ} \mathrm{N}\right.$, blue $)$, tropics $<T>$ tro $\left(30^{\circ} \mathrm{S}-30^{\circ} \mathrm{N}\right.$, red $)$, and global $<T>$ glo $\left(90^{\circ} \mathrm{S}-90^{\circ} \mathrm{N}\right.$, black $)$.

where $Q$ is the zonal mean diabatic temperature tendency (in the notation of Andrews et al, this term is $\left.\bar{J} / c_{p}\right), N$ is the buoyancy frequency, $H$ the scale height, $R$ the gas constant for air, and $w^{*}$ is the diabatic zonal mean residual vertical velocity (for definition, see Eq.( 7.2.3) of Andrews et al., 1987). Note that we have dropped the overbar commonly used for zonal mean quantities (e.g. $\left.\bar{w}^{*}\right)$ in order to comply with our previously defined conventions.

Assuming that the diabatic heating term can be approximated by Newtonian cooling (where the diabatic heating is linearly proportional (with factor $k_{\text {rad }}$ ) to the difference between temperature and a "radiative equilibrium" temperature $T_{\mathrm{E}}$ ), one gets

$k_{\mathrm{rad}}\left(T_{\mathrm{E}}-T\right)=\left(N^{2} H / R\right) \cdot w^{*}+\frac{\partial T}{\partial t}$
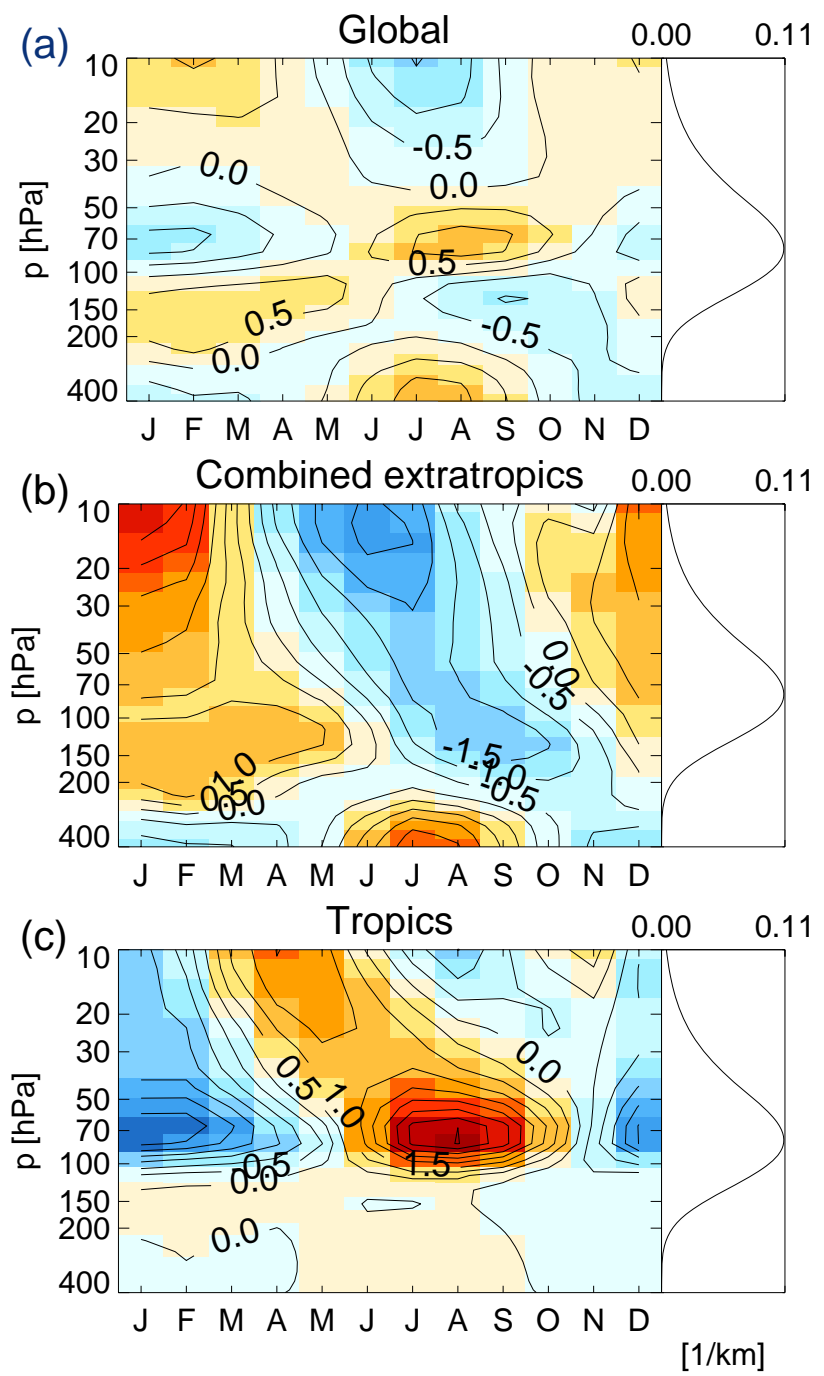

Fig. 3. Vertical structure of the area-weighted mean annual cycle of temperatures based on ERA-Interim: (a) global, (b) combined extratropics, (c) tropics. Contour and color increment is $0.5 \mathrm{~K}$. To the right of each panel is the MSU-4 weighting function (per kilometer) shown.

which is Eq. (1) of YHW94 (note that for the radiative equilibrium temperature, we follow the notation of Andrews et al. (1987), whereas YHW94 use the symbol $T_{0}$ ). One interpretation of this equation is that changes in $T$ can be forced either by changes in $w^{*}$ or by changes in $T_{\mathrm{E}}$. This interpretation needs care, since Eq. (4) is actually one of a coupled set of dynamical equations for zonal mean quantities in which variations in $T_{\mathrm{E}}$ and mechanical forcing, e.g. a wave-induced force, are most sensibly regarded as forcings on the dynamical variables, which include $T$ and $w^{*}$ (e.g. Haynes et al., 1991 and references therein). In this sense $w^{*}$ in Eq. (4) is forced (non-locally) by variations in $T_{\mathrm{E}}$ and by mechanical forcing, but the balance expressed by Eq. (4) does not allow prediction of $w^{*}$, and how it may change in response to 
variation in $T_{\mathrm{E}}$. Also, a given change in $T_{\mathrm{E}}$ does not necessarily imply the same change in $T$ since part of the response may appear as a meridional circulation. Detailed calculation of the temperature change requires a zonally symmetric dynamical calculation of the type reported by Haynes et al. (1991).

Let us now consider the global average of Eq. (4), and furthermore follow YHW94 in assuming that $k_{\text {rad }}=$ const. and $N^{2}=$ const. (These assumptions will be discussed further below).

$$
\begin{aligned}
& \left\langle T_{\mathrm{E}}\right\rangle_{\mathrm{glo}}-\langle T\rangle_{\mathrm{glo}}=\frac{N^{2} H}{k_{\mathrm{rad}} R} \cdot\left\langle w^{*}\right\rangle_{\mathrm{glo}}+1 / k_{\mathrm{rad}}\left\langle\frac{\partial T}{\partial t}\right\rangle_{\mathrm{glo}} \\
& \rightarrow\left\langle T_{\mathrm{E}}\right\rangle_{\mathrm{glo}}-\langle T\rangle_{\mathrm{glo}}=1 / k_{\mathrm{rad}}\left\langle\frac{\partial T}{\partial t}\right\rangle_{\mathrm{glo}}
\end{aligned}
$$

where we have used that mass conservation demands that the global integral of the residual circulation is zero (i.e. $\left\langle w^{*}\right\rangle_{\text {glo }} \equiv 0$ ). In the absence of a process forcing variations in global mean radiative equilibrium temperatures (i.e. $\left\langle T_{\mathrm{E}}\right\rangle_{\mathrm{glo}}=$ const.), global mean temperatures evolve in time as $\langle T\rangle_{\mathrm{glo}}(t)=\left\langle T_{\mathrm{E}}\right\rangle_{\mathrm{glo}}+A e^{-k_{\mathrm{rad}} t}$, i.e. the global mean temperature converges towards the global mean radiative equilibrium temperature (for $A \neq 0$ the system is initially out of thermodynamic equilibrium). It follows from the above assumptions and considerations that:

i There can be an annual cycle in global mean temperature only if there is an annual cycle in global mean radiative equilibrium temperature. Note an annual cycle in local radiative equilibrium temperatures may not imply necessarily an annual cycle in the global mean. For example, radiative equilibrium temperatures could have a large amplitude annual cycle at high latitudes, but if these compensate between the two hemispheres there will be no annual cycle in the global mean.

ii Conversely, if $T_{\mathrm{E}}$ is constant in time then an annual cycle in $w^{*}$ cannot give an annual cycle in global mean temperature, i.e. the resulting annual cycle in temperature will compensate perfectly between tropics and extratropics. But note that perfect compensation will also occur between the two parts of any latitudinal partition of the entire globe when weighted by their respective areas.

Note that YHW94 make the hypothesis that the compensated part (i.e. that part of the variability that averages to zero when averaged globally) of the annual cycle in $T$ is driven by $w^{*}$ only in the sense of Eq. (4). But this is a hypothesis only it cannot be deduced logically that there is no driving of the compensated part of temperature variations by variations in $T_{\mathrm{E}}$ (in particular by the compensated part of $T_{\mathrm{E}}$ ).

The situation gets considerably more complicated if we allow $k_{\text {rad }}$ and/or $N^{2}$ to vary. In particular, in this case global mean temperatures may vary in time even if $\left\langle T_{\mathrm{E}}\right\rangle_{\mathrm{glo}}=0$. For example, a latitudinal structure in thermal stratification $\left(N^{2}=f(\phi)\right)$ leads to an imbalance in equation 5 because in general $\left\langle N^{2}(\phi) \cdot w^{*}(\phi)\right\rangle_{\mathrm{glo}} \neq 0$. Hence, interpretation of global mean temperatures, and relations between temperatures of selected latitude bands is in principle not straightforward.

In the previous section we have shown that in fact global mean temperatures on lower stratospheric pressure levels are not constant in time, which challenges the results of YHW94. In the following, we try to quantify how variations in radiative equilibrium temperatures, and the latitudinal structure of $N^{2}$, modify the conclusion of YHW94.

\subsection{The latitudinal structure of thermal stratification}

Figure $4 \mathrm{a}$ shows the latitude-height distribution of $N^{2}$ calculated from the climatological mean, zonal mean ERAInterim temperature distribution. Of particular importance here is that, in addition to the obvious vertical variations, there is a substantial variation with latitude on each level in the layer of interest. Fig. $4 \mathrm{~b}$ shows that at $67 \mathrm{hPa}, N^{2}$ in the extratropics is throughout the year about $25-45 \%$ less than in the inner tropics.

The implication is that the part of the annual cycle in temperature forced by the residual circulation (in the sense of Eq. 4) would give larger amplitude temperature anomalies in the tropics than in the extratropics and the global mean of this part would not vanish.

\subsection{Ozone variations}

Figure 5a shows the ozone concentration variations at $70 \mathrm{hPa}$ based on HALOE measurements. Fig. 5b shows the corresponding temperature change under the seasonally evolving fixed dynamical heating approximation. Results using a different radiative transfer code (Fu-Liou code) are very similar (not shown).

Under the Newtonian cooling approximation, the temperature adjustment required for fixed dynamical heating is identical to the change in radiative equilibrium temperature (discussion below). Comparison of Fig. 5 with Fig. 2 shows that the calculated change in radiative equilibrium temperature due to the annual cycle in ozone is, in relation to the observed temperature variation, small in the extratropics whereas the ratio is about $1 / 3$ in the tropics. Hence, the calculations suggest that ozone related variations in $T_{\mathrm{E}}$ strongly amplify the tropical temperature variations (which is consistent with the results of Chae and Sherwood (2007) who studied the problem using a radiative-convective model with imposed stratospheric upwelling), and consequently cause an imbalance between tropics and combined extratropics.

As pointed out before, some care is needed for the interpretation of the seasonal variation in $T_{\mathrm{E}}$ and its relation to the seasonal variations in observed temperature. From a 
(a)

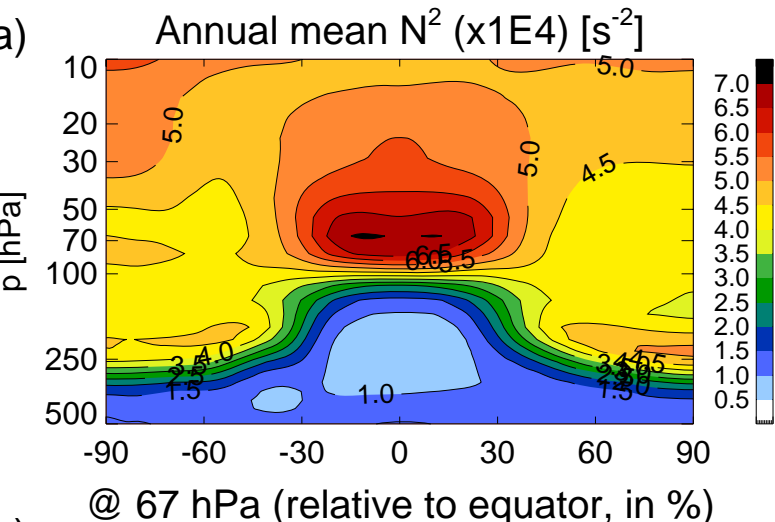

(b)

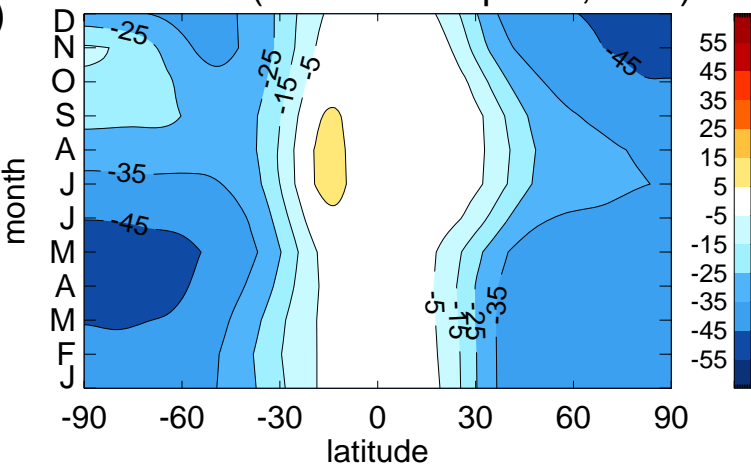

Fig. 4. (a) Buoyancy frequency $\left(N^{2}\right)$ calculated from climatological annual mean, zonal mean temperatures. (b) Ratio of $N^{2}(\phi)$ (calculated from climatological monthly mean data) to value at equator $\left(N^{2}(\phi=0)\right)$, expressed in percent.

diagnostic point of view, where the atmospheric temperature $T$ and residual circulation $w^{*}$ are given, Eq. (4) yields an annual cycle in diabatic heating $Q$ that is in agreement with that of the "real" $Q$ only if the annual cycle in $T_{\mathrm{E}}$ is taken into account. For a time-constant $T_{\mathrm{E}}$, Eq. (4) would yield variations in $Q$ that are larger than those of the "real" $Q$ and in general $\left\langle w^{*}\right\rangle_{\text {glo }} \neq 0$ (i.e. yields a violation of mass conservation). As such, the temperature change calculated with the SEFDH calculation can be interpreted as the contribution of ozone variations to the annual cycle of observed temperatures for a given $w^{*}$. For a given mechanical forcing, however, a change in radiative equilibrium temperature yields a temperature response that is generally smaller, since - expressed in terms of Eq. (4) - part of the change in $T_{\mathrm{E}}$ will be compensated by the dynamical heating term. For the case analysed here, where the change in $T_{\mathrm{E}}$ is relatively broad in latitude, it is likely that the resulting change in temperature is a substantial fraction of the change in $T_{\mathrm{E}}$.
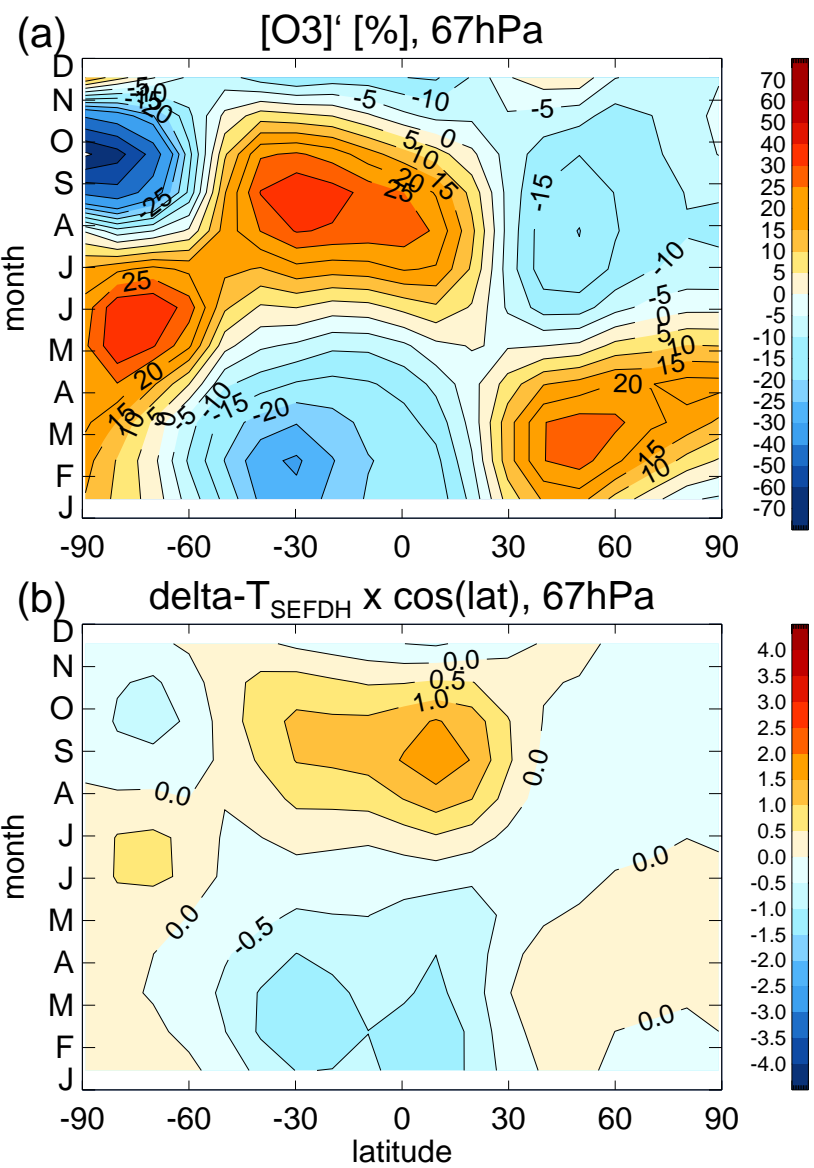

Fig. 5. (a) The climatological mean annual cycle of ozone concentrations from HALOE (anomalies from annual mean, in percent). (b) The corresponding temperature adjustment under the seasonally evolving fixed dynamical heating assumption; area-weighting for comparison with Figs. 1b, 2b.

\subsection{Model with adjustments for ozone-induced varia- tions in equilibrium temperature and the latitudinal structure of $N^{2}$}

In order to quantify the effect of ozone and $N^{2}$ on the balance between tropical and combined extratropical temperatures we introduce an adjusted temperature as follows (see Eq. 4):

$T_{\text {adj }}(\phi, t) \equiv\left(T(\phi, t)-\Delta T_{\text {ozone }}(\phi, t)\right) \frac{N^{2}(\phi=0, t)}{N^{2}(\phi, t)}$

where $\Delta T_{\text {ozone }}$ is the temperature difference calculated with the SEFDH calculation (as shown in Fig. 5b), and the second term is the (time dependent) correction for the latitudinal structure of $N^{2}$ (as shown in Fig. 4). The adjusted temperatures for the effects individually are

$T_{\text {adj, } \mathrm{O}_{3}}(\phi, t) \equiv T(\phi, t)-\Delta T_{\text {ozone }}(\phi, t)$ 

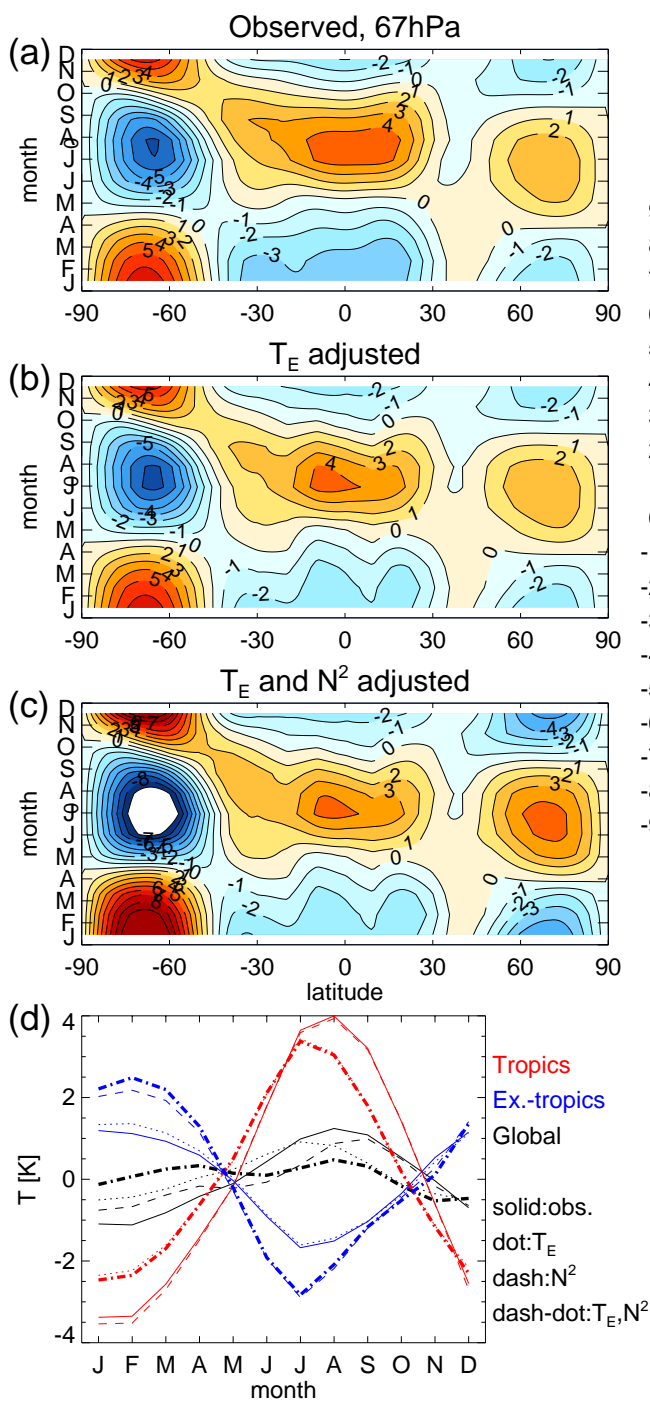

Fig. 6. (a) The annual cycle of area-weighted temperatures at $67 \mathrm{hPa}$ in ERA-Interim (color coded contours, values outside colorbar in white). (b) Ditto for the temperature adjusted by the change in equilibrium temperature in response to ozone variations (Eq. 8). (c) Ditto for the temperature adjusted by the change in equilibrium temperature in response to ozone variations, and latitudinal structure in $N^{2}$ (Eq. 7). (d) The annual cycles of area-integrated temperatures (black: global, red: tropics, blue: combined extratropics). The solid lines are for the observed (ERA-Interim) temperatures as shown in (a), the dotted lines for the ozone-related adjustment (Eq. 8, corresponding to panel (b)), the dashed lines for the $N^{2}$ adjusted temperature (Eq. 9), and the bold dash-dotted lines for the temperature adjusted for both ozone and $N^{2}$ (Eq. 7, corresponding to panel (c)).

$T_{\mathrm{adj}, \mathrm{N} 2}(\phi, t) \equiv T(\phi, t) \frac{N^{2}(\phi=0, t)}{N^{2}(\phi, t)}$.

Figure 6a shows the observed temperatures, panel (b) the temperatures adjusted with $\Delta T_{\text {ozone }}$ (i.e. subtracting the data shown in Fig. 5b from Fig. 6a), and panel (c) the fully scaled temperatures as given by Eq. (7). Note the amplification at high latitudes is due to calibration against $N^{2}$ at the equator in Eqs. (7 and 9).

Figure 6d shows the global, tropical and combined extratropical annual cycle of the adjusted temperatures. The figure shows that in terms of amplitude the effect from ozone is slightly larger than that from the latitudinal structure of $N^{2}$, and that the effects from ozone and $N^{2}$ on the adjusted temperatures are phase shifted by about 2 months. Compared to observed temperatures, the temperatures adjusted for $N^{2}$ and $T_{\mathrm{E}}$ (Eq. 7) show substantially better compensation between tropics and extratropics except for NovemberDecember. This result suggests that the two selected aspects - the seasonality in ozone mixing ratios and the latitudinal structure in $N^{2}$ - contribute substantially to the annual cycle in observed lower stratospheric temperatures.

The remaining slight imbalance between tropics and combined extratropics of the adjusted temperatures may have several reasons. First, the radiative transfer calculations may be not exact replications of the effect in reality, not least also because the ozone fields used for the calculations may not be exact. Second, other radiative effects, in particular the annual cycle in lower stratospheric water vapour mixing ratios, have not been included in our analysis. Radiative transfer calculations (not shown in this paper) using the fixed dynamical heating assumption (i.e. calculations similar to those shown for ozone) show that the temperature adjustment for the annual cycle in water vapour around $70 \mathrm{hPa}$ is about an order of magnitude smaller than that for ozone. Hence, we emphasize in this paper the role of ozone, but note that the much smaller inbalance between tropics and combined extratropics remaining after taking into account the effect of ozone and the latitudinal structure of static stability may be also due to the radiative impact of the annual cycle of water vapour mixing ratios. Finally, the Newtonian cooling approximation with a constant radiative relaxation time scale that is independent of variations in equilibrium temperature may not be adequate to describe the system (see also the calculations by Hitchcock et al., 2010). It is straightforward to show that $k_{\mathrm{rad}}$ is a function of $T_{\mathrm{E}}$, which also has implications for the estimation of $\Delta T_{\text {ozone }}$ (i.e. the equivalence to temperature adjustment under the fixed dynamical heating assumption is no longer given).

Although we find that the amplitudes of effects are quite robust, even small errors from any of these sources of error can slightly distort the phasing of the cycles, which quickly give a noticable error with respect to global compensation. Assessment of the validity of the adjusted temperature (Eq. 7) version of Eq. (4) may be more rewarding with data from a coupled chemistry-climate model, where the data (ozone variations and resulting temperature changes from radiative transfer model) are fully self-consistent.

The robust result of our analysis, however, is that around $70 \mathrm{hPa}$ the variations in radiative equilibrium temperatures as a result of ozone variations make a significant contribution 
to actual temperature variations in the tropics. Further, these variations in radiative equilibrium temperatures and the latitudinal structure of $N^{2}$ each give a temperature difference between tropics versus combined extratropics of about $1 \mathrm{~K}$ (equivalent to a variation in the global mean of $1 / 2 \mathrm{~K}$ ). Added together, these two aspects can account for much of the observed amplitude in global mean temperatures (which is about $1 \mathrm{~K}$ ). An important and subtle aspect of this result is that the ozone variations, in turn, are also a consequence of the dynamical processes controlling the residual circulation. Ozone concentrations in the tropical lower stratosphere can be understood to leading order from a balance between upwelling and production (Avallone and Prather, 1996). About half of the amplitude of seasonal variations of ozone concentrations on pressure levels arises from the seasonal cycle of the pressure of isentropic levels (a direct consequence of $w^{*}$ on $T$ in Eq. 4). The remainder has been attributed to seasonal variations in upwelling and in-mixing from the extratropics (see Randel et al., 2007; Konopka et al., 2009) which are both processes related to the seasonal variability of the Brewer-Dobson circulation, and possibly an influence from deep convection (Folkins et al., 2006). As such the ozone variation acts as an inherent amplifier of temperature variations, though in the absence of a precise physical model of this amplification it remains an open question whether the amplification factor is a function of timescale (and therefore different for annual and interannual variations).

\section{Interannual variability and trends}

Understanding the annual cycle from a mechanistic point of view (in terms of interaction of dynamics, tracers and radiation) is essential for the prediction of changes in the upper troposphere/lower stratosphere in a changing climate, and in turn would allow for consistency checks of measured temperature timeseries. It has already been noted by YHW94 that interannual variability of lower stratospheric temperatures as measured by MSU-4 has the same compensated pattern as the mean annual cycle. This has been further exploited more recently by Fu et al. (2010) and Ueyama and Wallace (2010) with MSU-4 temperature data. Given the vertical averaging of the MSU data over atmospheric layers whose temperatures may be controlled by different processes, we explore here the see-saw pattern of temperature variations on a fixed pressure level in the lower stratosphere.

Figure 7 shows the relation between seasonal and interannual timescale of tropical-extratropical temperatures on $67 \mathrm{hPa}$ from ERA-Interim. Fig. 7a shows that, as discussed before, the slope for extratropical temperature as function of tropical temperature of the annual cycle at $67 \mathrm{hPa}$ is only about $-1 / 2$, and not -1 . Further, the figure shows that the path of the mean annual cycle follows an ellipsoid rather than a straight line.
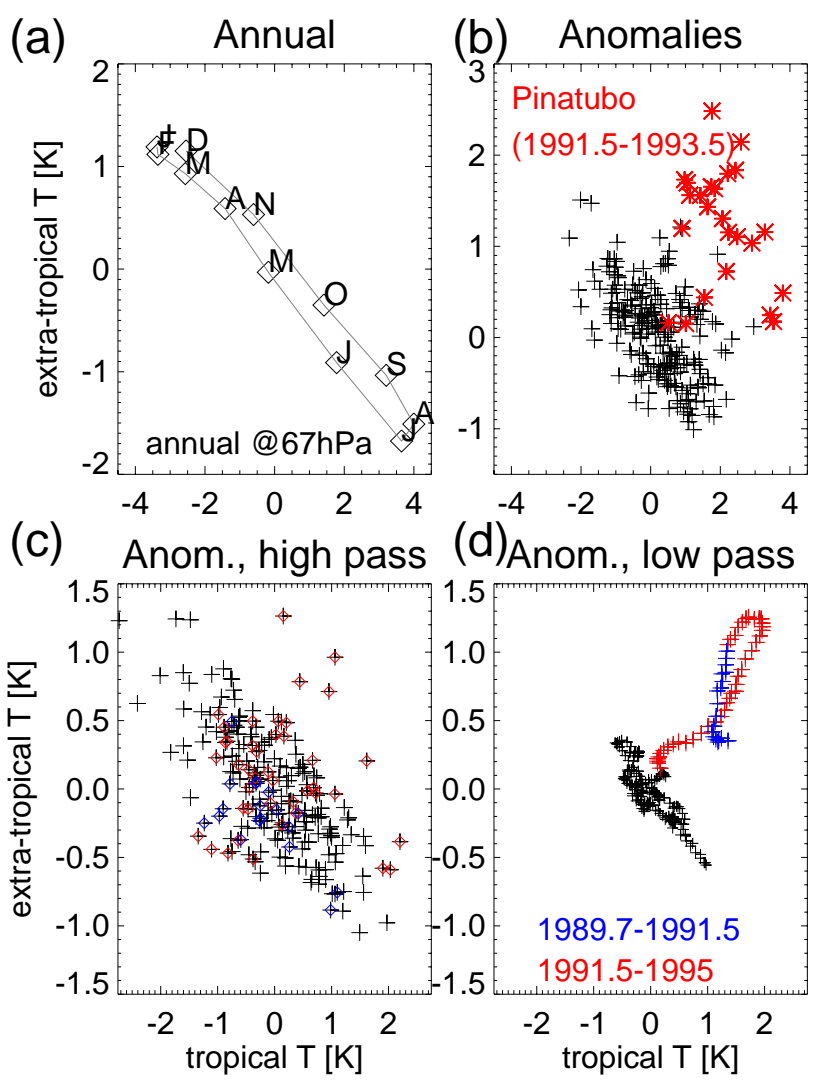

Fig. 7. Temperature correlations tropics-extratropics based on ERA-Interim data at $67 \mathrm{hPa}$. (a) Climatological mean annual cycle (data from 1995-2009). (b) Interannual anomalies after subtraction of mean annual cycle. Red asterisks show data of period of anomalous stratospheric aerosol loading following the eruption of Pinatubo. (c) High-pass filtered version of interannual variability (24-month running mean subtracted from original timeseries). Data points prior to and following Pinatubo eruption are shown in blue and red, respectively. (d) The low-pass filtered data, note that 24month averaging kernel leads to loss of 24 months of data, and to smearing out of the Pinatubo-related variations.

Figure $7 \mathrm{~b}$ shows that except for the Pinatubo period, interannual variability follows closely the pattern of seasonal variability. The close relation between annual cycle and interannual variability becomes even clearer when we apply a high-pass filter to the (interannual) timeseries. The rationale for applying a high-pass filter is that variations in the strength of the stratospheric residual circulation do happen also on relatively short timescales (weeks to months), while radiative effects from changes in tracers and aerosol that are not coupled to the strength of the residual circulation typically have a longer timescale. For example, substantially enhanced stratospheric aerosol levels following the Pinatubo eruption were observed for about 2 years, and radiative effects from increases in long-lived greenhouse gases lead to a very slow drift in temperatures. 
Figure $7 \mathrm{c}$ shows the high-pass filtered interannual variability, where the applied filter subtracts the (running) mean over 24 months (shown in Fig. 7d) from the original timeseries. The figure shows that the outliers seen in panel (a) arise from a decorrelation on longer timescales. For this timeseries, the outliers are the consequence of the latitudinal variation in the change of radiative equilibrium temperature from the Pinatubo aerosol. Conversely, the known drift in ERA-Interim temperatures with the introduction of COSMIC data in 2006 (see Liu et al., 2010) does not have an obvious impact on the signal, presumably because the temperature drift was similar at all latitudes.

Figure 8a shows the profiles of the slope between extratropical and tropical temperature variations (determined from total least squares linear fit) of the mean annual cycle determined for the period 1994-2009 (values connected with solid line). In order to obtain an uncertainty estimate for the slopes of the mean annual cycle and interannual variability, we used a bootstrapping approach whereby we calculated 100 random sample realisations for data of the period 1994-2009, and calculated the slope of the mean annual cycle of that sample, and, for each representation of the mean annual cycle, the corresponding slope of the interannual variability. The means (triangles) and \pm 2 standard deviations ("error bars") of that distribution are also shown. For the calculation of the high-pass filtered interannual variability we used 3 different filters, each with a 24-month width: rectangle (i.e. running mean), triangle and Nuttall. These 3 filter types have rather different characteristics; the fact that the determined slopes are virtually independent of the filter type illustrates the robustness of the results. Fig. 8b shows the correlation coefficients for the high-pass filtered (for each filter) data based on the annual cycle of the period 1994-2009.

Figures 7 and 8 show that low-pass filtering of interannual variability yields a compact relation between tropics and combined extratropics, and that the slopes of the variability on seasonal and interannual timescale are very similar around $70 \mathrm{hPa}$. This supports the notion that (but is not proof of) in this layer the annual cycle and interannual variability are driven by the same mechanism. It remains to be shown in future work whether the small differences in the slope in the layer $90-50 \mathrm{hPa}$ can be interpreted in a geophysically meaningful sense (for example, due to sensitivity of the ozone response to the timescale of the dynamical forcing).

Figure 9 shows that the see-saw pattern is also observed with annual mean temperature data. The figure compares data from ERA-Interim, ERA-40 and the so-called "RATPAC-A" data (see Free et al., 2005). As the data are annual means, the high-pass filtering in this case is done by subtraction of the 3-year running mean of the original timeseries. Probably the most interesting aspect of the figure is how dramatically the slope of the correlation changes with the isolation of the higher frequency variability. In the unfiltered data, the correlations between tropics and extratropics are positive due to, presumably, trends in greenhouse gas con-

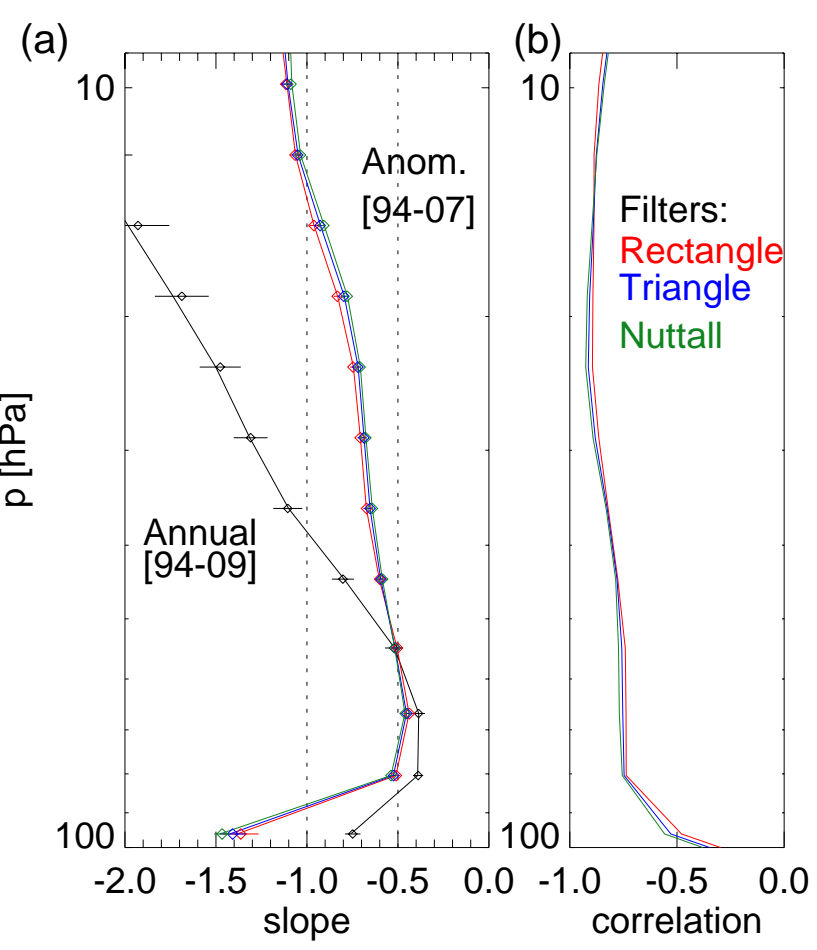

Fig. 8. Temperature correlations tropics-extratropics based on ERA-Interim data at $67 \mathrm{hPa}$. (a) Slope of linear fits (fitted in tropical and combined extratropical temperatures) to the annual (black) and high-pass filtered interannual variability. The colors refer to the filter used for band-pass filtering, filter types as indicated in panel (b). Dashed lines indicate slopes of $-1 / 2$ and -1 . Error bars and means calculated based on slope distribution calculated from bootstrapping the sample for the mean annual cycle; solid line connects slopes obtained with the original sample. (b) The correlation coefficient of the interannual variability for the period 1994-2007, based on the annual cycle of the period 1994-2009. All filters (rectangle, triangle and Nuttall) use a width of 2 years (24 samples); consequently the correlations are calculated for the period 1995-2008.

centrations and polar ozone depletion (i.e. both tropics and extratropics have a cooling trend due to a cooling trend in radiative equilibrium temperatures at all latitudes). Conversely, the high-pass filter isolates the signal from variations in the stratospheric residual circulation, where the tropics and extratropics have a negative correlation with a slope near $-1 / 2$. The two longer timeseries (ERA-40: -0.39 ; and RATPACA: -0.36) have slopes that are close to that of the monthly mean ERA-Interim data (see Fig. 7e), while that of the annual mean ERA-Interim data $(-0.65)$ is steeper. For the period 1995-2008, the slope of the RATPAC-A data $(-0.81)$ is even steeper than that of ERA-Interim for the same period $(-0.68)$. This shows that there is quite some uncertainty in the exact value of the slope, as it may vary both with period considered and with the frequency range of the highpass filter. 
(a)

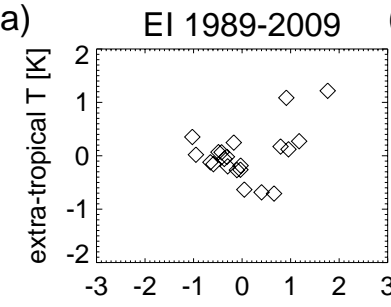

(c)

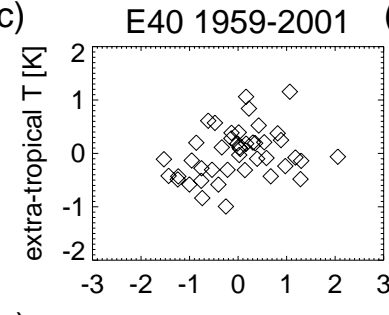

(e)

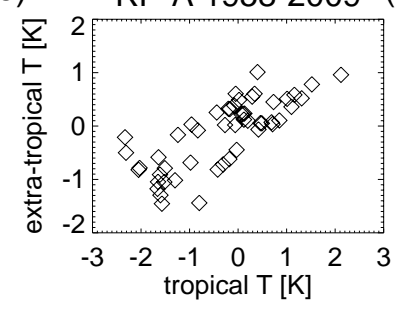

(b) El hi-pass, 1990-2009

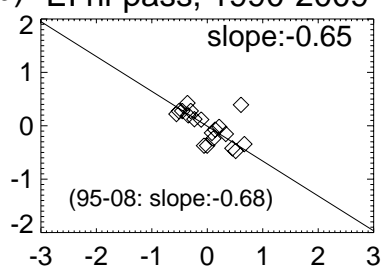

(d) E40 hi-pass, $1960-2000$

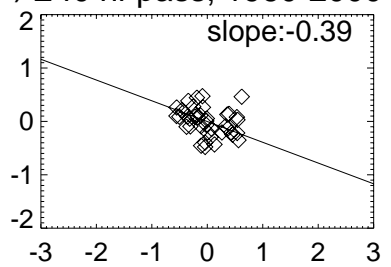

(f) RP-A hi-pass, 1959-2008

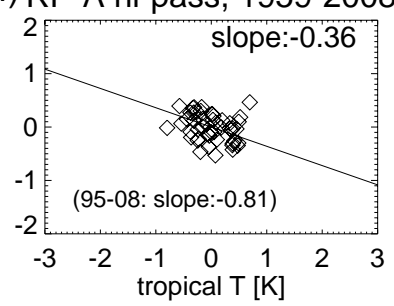

Fig. 9. Temperature correlations tropics-extratropics for annual means as reported (left column) and after high-pass filtering (right column, 3-year running mean subtracted from original timeseries). (a) ERA-Interim data at $67 \mathrm{hPa}, 1989-2009$. (b) Ditto, hi-pass filtered. (c) ERA-40 data at $70 \mathrm{hPa}, 1959-2001$. (d) Ditto, hi-pass filtered. (e) RATPAC-A data at $70 \mathrm{hPa}, 1958-2009$. (f) Ditto, hipass filtered. Slopes in panels $(\mathbf{b}, \mathbf{d}, \mathbf{f})$ refer to data periods as indicated in plot titles. For ERA-Interim and RATPAC-A the slopes have been calculated also for the common period 1995-2008 (see bracketed text in panels $(\mathbf{b} / \mathbf{f}))$.

Construction of a proxy for variations in the stratospheric residual circulation (which may include the effect of dynamical-radiative feedbacks from changes in tropical lower stratospheric ozone) from the variations in tropical and extratropical temperatures is straightforward (for example, one can take the scalar product of the vector of the observed mean correlation with the timeseries of the correlation), but beyond the scope of this paper.

\section{Conclusions}

We have shown that the observed compensation between annual temperature variation in the tropics and in the combined extratropics in MSU-4 results from particular properties of the MSU-4 weighting function and does not apply to temperatures on individual pressure surfaces. We have also shown that variations in radiative equilibrium temperature induced by changes in ozone contribute significantly to the observed annual cycle in temperature in the tropical lower

stratosphere. The resulting description of the annual cycle in temperature is therefore more complex than that proposed by YHW94, who noted that the major part of the annual cycle in MSU-4 temperatures is compensated and therefore can potentially (but not necessarily) be described only by the effect of the dynamically forced residual circulation without any need for a contribution from radiative equilibrium temperatures. In our description there is a much more important role for the variation in radiative equilibrium induced by ozone variations. These ozone variations are dynamically induced and therefore the effect on temperatures should be regarded as an enhancement of dynamical effects, not as something independent from dynamical effects. Representation of ozone variations and their effects on temperature, and the latitudinal variation of stratification should be included in simplified models of the lower stratosphere.

Finally, we have shown that around $70 \mathrm{hPa}$, the slopes of the correlation between tropical and combined extratropical temperatures of the mean annual cycle and interannual variability on shorter timescales (up to a few years) are similar. Hence, the annual cycle, including the amplification of temperature variations from the dynamical-chemical-radiative interaction, may serve as a model for interannual variability and trends in lower stratospheric temperatures.

Acknowledgements. We thank RSS for providing the weighting functions of the MSU channels. MSU data are produced by Remote Sensing Systems and sponsored by the NOAA Climate and Global Change Program. Data are available: atwww.remss.com. We thank NOAA NCDC for providing the RATPAC-A data, which was retrieved from http://www1.ncdc.noaa.gov/pub/data/ratpac. We thank ECMWF for providing access to ERA-interim data. Finally, we thank 3 anonymous reviewers and the editor for their constructive and helpful reviews.

Edited by: T. J. Dunkerton

\section{References}

Avallone, L. M. and Prather, M. J.: Photochemical evolution of ozone in the lower tropical stratosphere, J. Geophys. Res., 101(D1), 1457-1461, 1996.

Chae, J. H. and Sherwood, S. C.: Annual temperature cycle of the tropical tropopause: A simple model study, J. Geophys. Res., 112, D19111, doi:10.1029/2006JD007956, 2007.

Edwards, J. M. and Slingo, A.: Studies with a flexible new radiation code I: choosing a configuration for a large-scale model, Q. J. Roy. Meteorol. Soc., 122, 689-719, 1996.

Folkins, I., Bernath, P., Boone, C., LEsins, G., Livesey, N., A. M., Thompson, K., and Walker, J. C.: Witte Seasonal cycles of $\mathrm{O}_{3}$, $\mathrm{CO}$, and convective outflow at the tropical tropopause, Geophys. Res. Letts., 33(16), L16802, doi:10.1029/2006GL026602, 2006.

Forster, P. M., Freckleton, R. S., and Shine, K. P.: On aspects of the concept of radiative forcing, Clim. Dynam., 13, 547-560, 1997.

Free, M., Seidel, D. J., Angell, J. K., Lanzante, J., Durre I., and Peterson, T. C.: Radiosonde Atmospheric Temperature Products for Assessing Climate (RATPAC): A new dataset of large- 
area anomaly time series, J. Geophys. Res., (110), D22101, doi:10.1029/2005JD006169, 2005.

Fu, Q. and Johanson, C. M.: Satellite-derived vertical dependence of tropical tropospheric temperature trends, Geophys. Res. Letts., 32, L10703, doi:10.1029/2004GL022266, 2005.

$\mathrm{Fu}$, Q. and Liou, K. N.: On the correlated K-distribution method for radiative-transfer in nonhomogeneous atmospheres, J. Atmos. Sci., 49(22), 2139-2156, 1992.

Fu, Q., Solomon, S., and Lin, P.: On the seasonal dependence of tropical lower-stratospheric temperature trends, Atmos. Chem. Phys., 10, 2643-2653, doi:10.5194/acp-10-2643-2010, 2010.

Fueglistaler, S., Legras, B., Beljaars, A., Morcrette, J.-J., Simmons, A., Tompkins, A. M., and Uppala, S.: The diabatic heat budget of the upper troposphere and lower/mid stratosphere in ECMWF reanalyses, Q. J. Roy. Meteorol. Soc., 135, 21-37, 2009a.

Fueglistaler, S., Dessler, A. E., Dunkerton, T. J., Folkins, I., Fu, Q., and Mote, P. W.: Tropical tropopause layer, Rev. Geophys., 47, RG1004, doi:10.1029/2008RG000267, 2009b.

Haynes, P. H., Marks, C. J., McIntyre, M. E., Shepherd, T. G., and Shine, K. P.: On the Downward Control of Extratropical Diabatic Circulations by Eddy-Induced Mean Zonal Forces, J. Atmos. Sci., 48(4), 651-678, 1991.

Hitchcock, P., Shepherd, T. G., and Yoden, S.: On the Approximation of Local and Linear Radiative Damping in the Middle Atmosphere, J. Atmos. Sci., 67, 2070-2085, 2010.

Holton, J. R., Haynes, P. H., McIntyre, M. E., Douglass, A. R., and Rood, R. B., and Pfister, L.: Stratosphere-troposphere exchange, Rev. Geophys., 33, 403-440, 1995.

Konopka, P., Gross, J.-U., Ploeger, F., and Müller, R.: Annual cycle of horizontal in-mixing into the lower tropical stratosphere, J. Geophys. Res., 114, D19111, doi:10.1029/2009JD011955, 2009.
Liu, Y. S., Fueglistaler, S., and Haynes, P. H.: Advectioncondensation paradigm for stratospheric water vapor, J. Geophys. Res., 115, D24307, doi:10.1029/2010JD014352, 2010.

Norton, W. A.: Tropical Wave Driving of the Annual Cycle in Tropical Tropopause Temperatures, Part II: Model results, J. Atmos. Sci., 63, 1420-1431, 2006.

Randel, W. J., Park, M. J., Wu, F., and Livesey, N.: A large annual cycle in ozone above the tropical tropopause linked to the Brewer-Dobson circulation, J. Atmos. Sci., 64, 12, 4479-4488, 2007.

Randel, W. J., Garcia, R. and Wu, F.: Dynamical Balances and Tropical Stratospheric Upwelling, J. Atmos. Sci., 65(11), 35843595, 2008.

Reed, R. J. and Vlcek, C. L.: The Annual Temperature Variation in the Lower Tropical Stratosphere, J. Amtos. Sci., 26, 163-167, 1969.

Rosenlof, K. H.: Seasonal cycle of the residual mean meridional circulation in the stratosphere, J. Geophys. Res., 100(D3), 51735191, 1995.

Russell, III, J. M., Gordley, L. L., Park, J. H., Drayson, S. R., Hesketh, W. D., Cicerone, R. J., Tuck, A. F., Frederick, J. E., Harries, J. E., and Crutzen, P. J.: The Halogen Occultation Experiment, J. Geophys. Res., 98, 10777-10798, 1993.

Simmons, A., Uppala, S., Dee, D., and Kobayashi, S.: ERAInterim: New ECMWF reanalysis products from 1989 onwards, ECMWF Newsletter, 110, 25-35, 2006.

Ueyama, R. and Wallace, J. M.: To what extent does highlatitude planetary wave breaking drive tropical upwelling in the Brewer-Dobson circulation?, J. Atmos. Sci., 67, 1232-1246, doi:10.1175/2009JAS3216.1, 2010.

Yulaeva, E., Holton, J. R., and Wallace, J. M.: On the Cause of the Annual Cycle in Tropical Lower-Stratospheric Temperatures, J. Atmos. Sci., 51(2), 169-174, 1994. 